\title{
Optimization of diagnostic procedures in primary health services to detect asymptomatic malaria
}

\author{
LAMBOK SIAHAAN $^{1, A-G}$, PUTRI EYANOER ${ }^{2, A, C, ~ D, ~ M E R I N A ~ P A N G G A B E A N ~}{ }^{1, A, B, F}$, \\ YOAN PANGGABEAN ${ }^{1, A, B, F}$
}

${ }^{1}$ Parasitology Department, Medical Faculty, University of Sumatera Utara, Medan, Indonesia

${ }^{2}$ Community Medicine Department, Medical Faculty, University of Sumatera Utara, Medan, Indonesia

A - Study Design, B - Data Collection, C - Statistical Analysis, D - Data Interpretation, E - Manuscript Preparation, F - Literature Search, G - Funds Collection

Summary Background. The biggest challenge today is the accuracy of diagnostic tools to detect asymptomatic malaria. Up to the present, a microscopic examination procedure is only performed on patients with fever; thus, finding asymptomatic malaria is quite impossible. A serial microscopic examination (SME) procedure on patients who are at risk of malaria would make it possible to detect asymptomatic malaria.

Objectives. This study was done to find cases of asymptomatic malaria through the optimization of malaria diagnostic procedures at the primary health care facilities in the Batubara District, North Sumatera Province of Indonesia.

Material and methods. SME was conducted for three consecutive days once a microscopic examination provided a negative result. A diagnosis of malaria is confirmed by optimization of routine microscopic examination (ORME). SME is then carried out on the $2^{\text {nd }}$ day (first SME), the $8^{\text {th }}$ day (second SME) and the $15^{\text {th }}$ day (third SME). An examination was declared negative once Plasmodium sp. is not found up to 500 high power field.

Results. SME of 1,597 patients who had negative results on the first microscopic examination revealed that 95 had submicroscopic malaria (5.9\%). This study found asymptomatic malaria in $20.3 \%$ of the study subjects (188 persons) at first microscopic examination, $3.7 \%$ (34 persons) at first SME and 3\% (28 persons) at second SME.

Conclusions. ORME and SME performed on people at risk of malaria provide the possibility to detect asymptomatic malaria.

Key words: asymptomatic diseases, malaria, primary health care, quality of health care, optimization diagnostic.

Siahaan L, Eyanoer P, Panggabean M, Panggabean Y. Optimization of diagnostic procedures in primary health services to detect asymptomatic malaria. Fam Med Prim Care Rev 2018; 20(1): 67-70, doi: https://doi.org/10.5114/fmpcr.2018.73706.

\section{Background}

Malaria is a parasitic disease that is still a major health problem in the Batubara District, one of 13 districts categorized as a hypoendemic malaria area in the North Sumatera Province of Indonesia. The disease can cause death, especially in high-risk groups, such as infants, toddlers and pregnant women [1].

The morbidity and mortality rate of malaria constantly fluctuates. Fluctuations of the prevalence of malaria occur all the time in many places in Indonesia, including in the southern district of Nias, one of the areas with the highest prevalence of malaria in the North Sumatera Province [2].

Fluctuations are influenced by many factors, including diagnosis, treatment, community behavior, vector density and other factors related to the life cycle of the parasite. The delay of diagnosis is influenced by the availability of diagnostic tools in each area. One of the causes of such fluctuations is failure to detect cases of asymptomatic malaria. Alves stated that there are 4-5 times more patients with asymptomatic malaria compared to symptomatic malaria [3].

Detection of malaria patients is generally done by waiting for the suspect to come to the health service for examination and treatment. The method is often known as Passive Case Detection (PCD) [4]. This method will certainly be difficult to discover asymptomatic malaria, especially for those who did not experienced fever [5]. Asymptomatic malaria patients generally do not report to health care facilities; however, they can be a source of transmission of new cases of malaria (gametocyte carrier) and a reservoir of parasites, which are vectors of infection [6]. The Plasmodium will form the reservoir in a vector, especially in hypoendemic malaria transmission, and it can potentially be the cause of an increase in cases of malaria [7]. Coura et al. stated that the inability to detect and treat $25 \%$ of cases of asymptomatic malaria could thwart the efforts to eliminate malaria [8].

Many countries have increased the efforts of malaria interventions towards malaria elimination. One of these efforts is to change the diagnosis from diagnosing the patients' disease into diagnosing the presence or absence of malaria parasites in patients with asymptomatic malaria. The number of cases of asymptomatic malaria is influenced by many factors, such as the age of patients, the density of parasites and the bites of insect [9]. Asymptomatic malaria can also occur in a chronic infection [10]. The biggest challenge now is finding asymptomatic malaria at an early stage [6], especially at primary health care facilities.

Detection of asymptomatic malaria has been performed using polymerase chain reaction (PCR), which is known to be more sensitive than a microscopic examination. However, PCR tests are very difficult to perform at primary health care facilities. This is due to high operational costs and the fact that performing such a test requires standard methodology and expertise [11]. Although less sensitive a than microscopic examination [12], rapid diagnostic tests (RDTs) could be used to detect asymptomatic malaria in hypoendemic areas, especially on periodic mass blood surveys [13]. A Rapid Diagnostic Test (RDT) is an alternative diagnosis commonly used in areas without a trained microscope reader, but the microscopic test is still the golden standard in diagnosis of malaria. 
PCR and microscopic examinations have the same capacity to identify species, but only a microscopic examination provides the possibility to calculate the density of parasites and identify the stage of parasitic development. Parasite density is needed in the evaluation of the effectiveness of malaria treatment, and estimating the density of the gametocytes of the parasite is particularly useful in the effort to control the transmission of disease [14]. Therefore, the optimization of a routine microscopic examination (ORME) at the primary care level may prove to be more useful in detecting asymptomatic malaria than the use of PCR assays.

ORME is done by increasing the volume of blood being examined and performing a serial microscopic examination (SME). Optimization will minimize the chance of misdiagnosis due to low parasite density. Furthermore, SME can be performed on any person at risk of malaria.

\section{Objectives}

The data presented here was part of a study designed to create a model for diagnosing asymptomatic malaria in the Batubara District in the North Sumatera Province of Indonesia. The Batubara District is a hypoendemic malaria area, as the estimated prevalence of parasites in children aged 2 to 9 years is less than 10\% [15]. This study is being carried out from March 2015 to March 2018, and its primary aim is to detect the presence of asymptomatic infections through the optimization of malaria diagnostic procedures at primary health care facilities.

\section{Material and methods}

\section{Study design}

This is a longitudinal study for a diagnostic test. Each study subject residing in the area was observed for 2 weeks. Data was collected from 4 primary health care facilities and 25 villages - from March until December 2015. Passive case detection (PCD) was done on patients treated at primary health care facilities with no symptoms of malaria (fever) and who were willing to participate in this study. At the same time, active case detection (ACD) was carried out on residents living with patients previously diagnosed with malaria (secondary data). ACD methods generally allow one to detect more cases of asymptomatic malaria than PCD.

This paper has been subjected to an ethics review by the ethical committee of the Medical Faculty, University of Sumatera Utara and has been favorably endorsed by the above-mentioned committee. Ethical clearance number: 252/KOMET/FK USU/2015.

\section{Laboratory methods}

Routine microscopic examination (RME) is the examination of a thick blood smear with a volume ranging from 3-4 $\mu \mathrm{l}$ blood (1 blood drop) stained with 3\% Giemsa and examined at up to 200 high power field [16]. ORME is an RME with one additional drop of blood to allow examination at up to 500 high power field. A thick blood smear was prepared by staining the glass slide with 2 drops of blood. SME is an RME performed several times once a negative result is obtained during the first examination, and it ceases once Plasmodium sp. has been found or when a specimen has been examined 3 times in a row. A thin blood smear examination is done to identify the species of Plasmodium. Parasite density calculation is performed at up to 500 high power field.

Malaria diagnosis is confirmed by ORME, as this was the golden standard in this study. If the first RME (Day 0) finds no Plasmodium sp., it is then followed by the first SME on the next day (Day 1). If the results are still negative, the SME is repeated on the $8^{\text {th }}$ day (second SME) and $15^{\text {th }}$ day (third SME). Microscopic examination will be terminated once Plasmodium sp. has been found or if the serial examination is done three times. Microscopic examinations are carried out by at least two experts who have been trained (certificated from the Indonesian Health Ministry) and have worked at the Parasitology Laboratory of the Medical Faculty, University of Sumatera Utara. In the case of differences in examination results, the tests are performed by a third diagnostician, and his result is used as the final decision.

\section{Statistical analysis}

A descriptive statistical analysis was performed to compare malaria classification and the etiology of malaria. Two-by-two tables were created to calculate point estimates and $95 \% \mathrm{Cls}$ for the sensitivity, specificity, positive and negative predictive value. The chi-square test was used to compare cases of asymptomatic malaria between each diagnostic procedure (RME, first SME and second SME) and mode detection (ACD and PCD).

\section{Results}

This study involved 927 patients with no fever out of a total of 2,478 subjects examined. An axillary temperature was obtained upon recruitment of all patients. Fever was defined as an axillary temperature $\geq 37.5^{\circ} \mathrm{C}$.

The ORME found that $26.9 \%$ of the study subjects had asymptomatic malaria, with Plasmodium vivax $(53.6 \%)$ being the most common etiological factor (Table 1).

\begin{tabular}{|l|l|l|l|}
\hline \multicolumn{3}{|l|}{ Table 1. Distribution of sample } \\
\hline No & Characteristic & $n$ & $\%$ \\
\hline 1. & Classification & 677 & 73.1 \\
& Non-Malaria & 250 & 26.9 \\
\hline & Asymptomatic malaria & 25 & 10.0 \\
\hline 2. & Species & 134 & 53.6 \\
& Plasmodium falciparum & 91 & 36.4 \\
& Plasmodium vivax & & \\
& P. falciparum + P. vivax & \\
\hline
\end{tabular}

188 persons ( $20.3 \%$ ) were found to be infected with asymptomatic malaria on D0, 34 persons (3.7\%) on D1 and 28 persons (3\%) on D8. No cases of asymptomatic malaria were confirmed on the third SME (D15). Diagnostic accuracy increases in highdensity samples (Table 2 ).

\begin{tabular}{|c|c|c|c|c|c|c|c|c|c|}
\hline \multicolumn{2}{|c|}{ Diagnostic procedures } & \multicolumn{2}{|c|}{$\operatorname{ORME}^{\mathrm{a}}(n)$} & \multirow{2}{*}{$\begin{array}{l}\text { Sensitivity } \\
\%)\end{array}$} & \multirow{2}{*}{$\begin{array}{l}\text { Specificity } \\
(\%)\end{array}$} & \multirow{2}{*}{$\frac{\mathrm{PPV}^{\mathrm{d}}}{(\%)}$} & \multirow{2}{*}{$\begin{array}{l}\text { NPV }^{e} \\
(\%) \\
\end{array}$} & \multicolumn{2}{|c|}{ Density $(x / \mu l)$} \\
\hline & & Positive & Negative & & & & & Mean & SD \\
\hline \multirow[t]{2}{*}{$\mathrm{RME}^{\mathrm{b}}$} & positive & 148 & 0 & \multirow[t]{2}{*}{78.7} & \multirow[t]{2}{*}{100} & \multirow[t]{2}{*}{100} & \multirow[t]{2}{*}{94.9} & \multirow[t]{2}{*}{444.04} & \multirow[t]{2}{*}{151.5} \\
\hline & negative & 40 & 739 & & & & & & \\
\hline \multirow[t]{2}{*}{$1^{\text {st }} \mathrm{SME}^{\mathrm{C}}$} & positive & 30 & 0 & \multirow[t]{2}{*}{88.2} & \multirow[t]{2}{*}{100} & \multirow[t]{2}{*}{100} & \multirow[t]{2}{*}{99.4} & \multirow[t]{2}{*}{883.53} & \multirow[t]{2}{*}{44.44} \\
\hline & negative & 4 & 705 & & & & & & \\
\hline \multirow[t]{2}{*}{$2^{\text {nd }} S \mathrm{SME}^{\mathrm{c}}$} & positive & 26 & 0 & \multirow[t]{2}{*}{92.9} & \multirow[t]{2}{*}{100} & \multirow[t]{2}{*}{100} & \multirow[t]{2}{*}{99.7} & \multirow[t]{2}{*}{1144.29} & \multirow[t]{2}{*}{44.01} \\
\hline & negative & 2 & 677 & & & & & & \\
\hline
\end{tabular}

${ }^{a}$ Optimization of routine microscopic examination; ${ }^{b}$ routine microscopic examination; ${ }^{c}$ serial microscopic examination; ${ }^{d}$ positive predictive value; e negative predictive value. 


\begin{tabular}{|c|c|c|c|c|c|c|c|}
\hline \multirow{2}{*}{\multicolumn{2}{|c|}{ Diagnostic procedures }} & $\mathrm{ACD}^{\mathrm{c}}$ & $P C^{d}$ & \multirow[t]{2}{*}{$p$} & \multirow[t]{2}{*}{$\mathrm{PR}^{\mathrm{e}}$} & \multicolumn{2}{|c|}{ Confidence Interval 95\% } \\
\hline & & \multicolumn{2}{|l|}{ (n) } & & & Min. & Max. \\
\hline \multirow[t]{2}{*}{$\mathrm{RME}^{\mathrm{a}}$} & positive & 122 & 66 & \multirow[t]{2}{*}{$0.368^{*}$} & \multirow[t]{2}{*}{1.033} & \multirow[t]{2}{*}{0.961} & \multirow[t]{2}{*}{1.109} \\
\hline & negative & 464 & 275 & & & & \\
\hline $1^{\text {st }} \mathrm{SME}^{\mathrm{b}}$ & positive & 24 & 10 & $0.773^{*}$ & 1.112 & 0.541 & 2.288 \\
\hline \multirow[t]{2}{*}{$2^{\text {nd }} S M E^{b}$} & positive & 17 & 11 & \multirow[t]{2}{*}{$0.384^{*}$} & \multirow[t]{2}{*}{1.014} & \multirow[t]{2}{*}{0.980} & \multirow[t]{2}{*}{1.050} \\
\hline & negative & 405 & 272 & & & & \\
\hline
\end{tabular}

${ }^{a}$ Routine microscopic examination; ${ }^{b}$ serial microscopic examination; ${ }^{c}$ active case detection; ${ }^{d}$ passive case detection; ${ }^{\mathrm{e}}$ prevalence ratio; ${ }^{*} p>0.05$.

The results show that the ORME had found cases of asymptomatic malaria more often than the RME. The SME performed on patients with no fever found $62(6.7 \%)$ asymptomatic malaria patients.

In general, the ACD found cases of asymptomatic malaria more often than the PCD in all diagnostic procedures, although the difference was not significant $(p>0.05)$ (Table 3). The results show the importance of active detection of asymptomatic malaria in people living in malaria-endemic areas, particularly those at a higher risk of malaria but not presenting with fever.

\section{Discussion}

Malaria is still the most prevalent mosquito-borne disease in Batubara, one of the most highly endemic areas in the North Sumatera Province in Indonesia. Detection of asymptomatic infections in primary health care facilities has become a crucial element to complete a malaria elimination program. Considering the challenge of eliminating asymptomatic malaria, the aim of this study was to evaluate the prevalence of cases of asymptomatic malaria based on microscopic examination in the Batubara District.

Many countries are scaling up malaria interventions towards elimination of the disease. This means that malaria diagnostics has to be oriented toward asymptomatic carriers, as well as towards patients presenting with fever. In fact, asymptomatic carriers act as parasite reservoirs and continuously transmit parasites to Anopheles mosquitoes [17].

Infections of asymptomatic malaria do not manifest with fever, but Plasmodium sp. is found on microscopic examination of blood specimens. Gametocytes present in the blood of patients can be a source of new infections (gametocyte carrier). Late diagnosis and treatment of patients with asymptomatic malaria increase the risk of malaria transmission and are a major obstacle in eliminating the disease [6].

The epidemiology of asymptomatic malaria is different in each region and depends on the endemicity. The prevalence of asymptomatic malaria is influenced by many factors, such as age, the density of parasites and insect bites $[9,18]$. Asymptomatic malaria may also occur in patients with chronic malaria infection [10].

At an early stage of the disease, asymptomatic malaria does not show any clinical symptoms, but when antiparasitic immunity fails to suppress parasite density, clinical symptoms do appear eventually [6]. Clinical symptoms are expected to appear two to four weeks later. Dysregulation of the immune system leads to the development of symptomatic malaria, which may not be detectable by microscopic examination (submicroscopic malaria) [19].

Microscopic examination as the standard diagnosis of malaria is expected to be optimized, especially for the early detection of malaria in primary health care facilities. Detection of asymptomatic malaria requires a diagnostic tool that has a high sensitivity, and microscopic examination accuracy improves when done serially. A negative result in the first microscopic examination does not rule out the diagnosis of malaria. SME can be repeated a maximum of 3 times.

In this study, the ORME has found 40/188 (21.3\%) infections of asymptomatic malaria, which was more than the RME, with the average density of parasites being 444.04 parasites/ $\mu$ l. At the same time, the SME found 56/62 (90.3\%) asymptomatic malaria patients, the parasite density increasing up to $1,144.29$ parasites/ $\mu$ l (Table 2). Asymptomatic malaria was still found during the second or third microscopic examination.

Detection of asymptomatic malaria is usually done using PCR. PCR use in primary health care facilities is limited due to its high cost, lack of standard methodology and a shortage of experts. In addition, PCR assays cannot be used to estimate the density of parasites or to identify their developmental stage. The accuracy of the microscopic examination is lower when compared with PCR. This has been widely demonstrated in epidemiological studies $[10,14]$. One of the factors that influences test accuracy is the amount of blood. Microscopic examination uses approx. $5 \mu \mathrm{l}$ of blood, while PCR requires approx. $200 \mu \mathrm{l}$ of blood for DNA isolation [11].

Therefore, optimization of microscopic methods at primary health care facilities should be done, among others, by using more blood volume and introducing serial microscopic examination. Harris stated PCR methods show a $25 \%$ higher accuracy in detecting asymptomatic malaria than RME [20]. Thus, it is expected that the optimization of RME can offset the superiority of PCR. This result is expected to reduce the transmission of the disease and accelerate malaria elimination [8].

The success of early detection is influenced by the method used. Passive case detection of asymptomatic malaria should not only be performed in patients with fever, but can be randomly performed on all patients attending primary health care services. This was confirmed by a study stating that not all malaria patients present with complaints of fever [5]. Active case detection can, however, be performed based on the findings of previous cases of malaria. Blood tests can be performed on residents who live close to malaria patients or by mass examination of blood samples from people who live in areas where malaria is reported throughout the whole year.

It should be noted that to successfully eliminate malaria in any given endemic region, one of the main requirements is active case detection. Periodically, people in endemic areas, with or without fever, should be tested to detect asymptomatic infections. It could be postulated that, as no cases of asymptomatic malaria have been found, the malaria elimination program is successful [19].

\section{Conclusions}

Detection of asymptomatic malaria in primary health care facilities can be improved through the optimization of routine microscopic examinations and by introducing serial microscopic examinations in patients at a higher risk of malaria but who present with no fever.

Acknowledgments. We would like to thank the health workers of health care services in the Batubara District, as well as the malaria program supervisor in the Batubara District, North Sumatera. We also wish to thank all the participants of this study and the Research Institutes of the University of Sumatera Utara. 
Source of funding: This paper was developed utilizing funds from the Research Institutes of the University of Sumatera Utara. Conflict of interest: The authors declare no conflict of interests.

\section{References}

1. Health Department of North Sumatra Province. Monthly Report Malaria Cases. 2015 (unpublished).

2. Siahaan L. Malaria Pasca Bencana Alam di Kabupaten Nias Selatan. Majalah Kedokteran Nusantara 2008; 41(3): 155-160 (in Indonesian).

3. Alves FP, Durlacher RR, Menezes MJ, et al. High prevalence of asymptomatic Plasmodium vivax and Plasmodium falciparum infections in native Amazonian populations. Am J Trop Med Hyg 2002; 66(6): 641-648.

4. Gueye CS, Sanders KC, Galappaththy GNL, et al. Active case detection for malaria elimination: a survey among Asia Pacific countries. Malaria Journal 2013; 12: 358.

5. Siahaan L. Gejala dan Tanda Klinis Malaria di daerah Endemis. Majalah Kedokteran Nusantara 2008; 58(6): $211-215$ (in Indonesian).

6. Lindblade KA, Steinhardt L, Samuels A, et al. The silent threat: asymptomatic parasitemia and malaria transmission. Expert Review of Anti-infective Therapy 2013; 11(6): 623-639.

7. Ahmed S, Galagan S, Scobie H, et al. Malaria hotspots drive hypoendemic transmission in Chittagong Hill Districts of Bangladesh. PLoS ONE 2013; 8(8): e69713, doi: https://doi.org/10.1371/journal.pone.0069713.

8. Coura JR, Suárez MM, Ladeia AS. A new challenge for malaria control in Brazil: asymptomatic Plasmodium infection - a review. Mem Inst Oswaldo Cruz 2006; 101(3): 229-237.

9. Geiger C, Agustar HK, Compaoré G, et al. Declining malaria parasite prevalence and trends of asymptomatic parasitaemia in a seasonal transmission setting in north-western Burkina Faso between 2000 and 2009-2012. Malaria Journal 2013; 12: 27.

10. Cheng Q, Cunningham J, Gatton ML. Systematic review of sub-microscopic $P$. vivax infections: prevalence and determining factors. $P$ LoS Negl Trop Dis 2015; 9(1): e3413, doi: 10.1371/journal.pntd.0003413.

11. Moreira CM, Shehada MA, Price RN, et al. A systematic review of sub-microscopic Plasmodium vivax infection. Malaria Journal 2015; 14: 360.

12. Siahaan L. Perbandingan rapid diagnostic test dan pemeriksaan mikroskopik pada diagnosis malaria. KESMAS Jurnal Kesehatan Masyarakat Nasional 2011; 5(6): 250-253 (in Indonesian).

13. Siahaan, L, Alrasyid H, Akbari R, et al. Rapid diagnostic tests to detect asymptomatic malaria in primary health care facilities in hypoendemic areas. Fam Med Prim Care Rev 2016; 18(4): 470-472.

14. Golassa L, Baliraine FN, Enweji N, et al. Microscopic and molecular evidence of the presence of asymptomatic Plasmodium falciparum and Plasmodium vivax infections in an area with low, seasonal and unstable malaria transmission in Ethiopia. BMC Infectious Diseases 2015; 15: 310, doi: https://doi.org/10.1186/s12879-015-1070-1.

15. World Health Organization. Disease surveillance for malaria elimination. An operational manual. World Health Organization 2012. Available from URL: http://apps.who.int/iris/bitstream/10665/44852/1/9789241503334_eng.pdf

16. World Health Organization. Basic malaria microscopy. WHO Library Cataloguing Switzerland 2010; 1(2): 21-29.

17. Suárez MMC, Cuervo P, Leoratti FM, et al. Cross sectional study reveals a high percentage of asymptomatic Plasmodium vivax infection in the Amazon Rio Negro area, Brazil. Rev Inst Med Trop Sao Paulo 2007; 49(3): 159-164.

18. Lo E, Zhou G, Oo W, et al. Low parasitemia in submicroscopic infections significantly impacts malaria diagnostic sensitivity in the Highlands of Western Kenya. PLoS ONE 2015; 10(3): e0121763, doi: https://doi.org/10.1371/journal.pone.0121763.

19. Okell LC, Bousema T, Griffin JT, et al. Factors determining the occurrence of submicroscopic malaria infections and their relevance for control. Nat Commun 2012; 3: 1237, doi: 10.1038/ncomms2241.

20. Harris I, Sharrock WW, Bain LM, et al. A large proportion of asymptomatic Plasmodium infections with low and sub-microscopic parasite densities in the low transmission setting of Temotu Province, Solomon Islands: challenges for malaria diagnostics in an elimination setting. Malaria Journal 2010; 9: 254.

Tables: 3

Figures: 0

References: 20

Received: 22.08.2017

Reviewed: 31.08.2017

Accepted: 16.10 .2017

Address for correspondence:

Lambok Siahaan, MD, PhD

Parasitology Department

Medical Faculty Universitas Sumatera Utara

Jl. Dr. Mansur no. 5

Medan 20155

Indonesia

Tel.: 062618126561772

E-mail: lamboksiahaan_fkusu@yahoo.com 